\title{
Reform and Practice of the Core Curriculum of Civil Engineering and Architecture Based on the "1+X" System
}

\author{
Yajuan Liu* \\ Chongqing Energy College, Chongqing 402260, China \\ *Corresponding author: Yajuan Liu, Liuyajuan_0510@163.com
}

Copyright: ( $) 2022$ Author(s). This is an open-access article distributed under the terms of the Creative Commons Attribution License (CC BY 4.0), permitting distribution and reproduction in any medium, provided the original work is cited.

\begin{abstract}
The " $1+\mathrm{X}$ " system has a great impact on the development of vocational education. Based on this system, it is imperative to carry out the reform and practice of the core curriculum of Civil Engineering and Architecture. Several vocational colleges have made attempts in the reform and practice of the curriculum, but the effect is not ideal. Under the influence of various factors, such as the lack of experience, there are also several problems in the reform and practice of the curriculum. Among them, the most apparent problems are as follows: the curriculum reform is not synchronized with the development of teaching materials, the pertinence of practical teaching is lacking, and the guidance provided for professional certificate examinations is not well-established. This paper specifically analyzes the problems existing in the reform and practice of the core curriculum of Civil Engineering and Architecture under the " $1+\mathrm{X}$ " system, and then puts forward effective strategies for these problems.
\end{abstract}

Keywords: " $1+X$ ” system; Civil engineering and architecture; Curriculum reform

Online publication: January 12, 2022

\section{Introduction}

Under the background of vocational education reform, the maturity of the teaching concept of Civil Engineering and Architecture has improved, and the reform and practice of its core curriculum has gained much attention. After the " $1+X$ " system was introduced, the curriculum reform and practice based on this system has become the main choice. More and more vocational colleges are making attempts at this level, but the actual effect is not ideal. It is an indisputable fact that there are some problems in its curriculum reform and practice. Considering the obvious restrictive effects of various problems, it is of great significance to explore effective strategies for the reform and practice of the core curriculum of Civil Engineering and Architecture under the " $1+\mathrm{X}$ " system.

\section{Reform and practice of the core curriculum of Civil Engineering and Architecture under the " $1+\mathrm{X}$ " system}

The reform and practice trend of the core curriculum of Civil Engineering and Architecture under the " $1+\mathrm{X}$ " system is apparent. It is directly related to the value of specific curriculum reform and practice ${ }^{[1]}$. On the one hand, the reform and practice of the core curriculum of civil engineering and architecture under the " $1+\mathrm{X}$ " system can greatly improve the innovation and effectiveness of the course teaching as well as the 
quality of professional teaching. On the other hand, it can deepen students' understanding of professional knowledge and help students better improve their basic professional skills as well as obtain professional certificates, so as to promote better development. This indicates that whether from the perspective of vocational education development and curriculum reform, or from the perspective of students' growth and development, it is necessary to actively carry out corresponding curriculum reform and practice under the " $1+X$ " system. For vocational colleges and civil architecture teachers, they also need to think more deeply about the reform and practice of its core curriculum.

\section{Problems existing in the reform and practice of the core curriculum of Civil Engineering and Architecture under the " $1+X$ " system}

\subsection{Unsynchronized curriculum reform with textbook development}

In the reform and practice of the core curriculum of Civil Engineering and Architecture under the " $1+\mathrm{X}$ " system, many vocational colleges are not keeping up with the development of school-based teaching materials, resulting in an asynchrony in the curriculum reform with the development of teaching materials ${ }^{[2]}$. Generally speaking, as long as curriculum reform is involved, it needs to be adjusted at the teaching level. In addition to selecting innovative teaching methods, it is also important to introduce new teaching contents. At this stage, the teaching of civil engineering and architecture in vocational education is highly dependent on the teaching materials, in which the content framework of the teaching materials determines the knowledge framework in the curriculum teaching. However, theoretical knowledge accounts for a large proportion in many teaching materials. Teaching based on the inherent curriculum teaching does not provide effective support for the reform and practice of its core curriculum under the " $1+X$ " system. At the same time, it does not provide sufficient support for the cultivation and improvement of students' professional skills. In the specific curriculum reform and practice, as the development of teaching materials is not synchronous in practice, the continuous use of previous teaching materials is not conducive to the reform and practice of the curriculum.

\subsection{Lacking pertinence in practical teaching}

In the reform and practice of the core curriculum of Civil Engineering and Architecture under the " $1+\mathrm{X}$ " system, the lack of pertinence in practical teaching is also a problem. Since the " $1+X$ " system emphasizes more on the cultivation of students' professional skills, it has become a goal for students to obtain relevant certificates of civil engineering based on the cultivation of professional skills. In this case, practical teaching has become the main form of teaching. Most vocational colleges are also driving the reform and practice of its core curriculum around practical teaching activities. Through analyzing the curriculum reform and practice of Civil Engineering and Architecture in several vocational colleges, it has been ascertained that although the importance of practical teaching is increasing, the pertinence of practical teaching is obviously lacking, which makes practical teaching a mere form. In the long run, it will be difficult to make a confounding breakthrough in the curriculum reform and practice.

\subsection{Inadequate guidance in professional certificate examinations}

In the reform and practice of the core curriculum of Civil Engineering and Architecture under the " $1+\mathrm{X}$ " system, the problem of inadequate guidance in certificate examinations is also apparent. Under the " $1+X$ " system, it is necessary to help students obtain as many certificates as possible throughout the course. However, from the perspective of its curriculum reform and practice, many vocational colleges and teachers have not been guiding students properly in preparing for these certificate examinations. It is extremely difficult for students to obtain multilevel certificates, such as in Building Information Modeling (BIM). The 
acquisition of these certificates requires students to put in a lot of effort, and it is also inseparable from the guidance provided in curriculum teaching. However, in the specific reform and practice of the core curriculum, the guidance provided for these examinations is not properly established, which makes it difficult for many students to obtain the relevant certificates; thus, the effect of the curriculum reform and practice under the " $1+\mathrm{X}$ " system is naturally below par.

\section{Strategies for the reform and practice of the core curriculum of Civil Engineering and Architecture under the " $1+X$ " system}

\subsection{Developing school-based teaching materials that are in line with the curriculum reform and practical needs}

In the reform and practice of the core curriculum of Civil Engineering and Architecture under the " $1+\mathrm{X}$ " system, vocational colleges should develop school-based teaching materials in line with the needs of curriculum reform and practice ${ }^{[3]}$. For example, a vocational college in Xi'an has made attempts for the reform and practice in the teaching of many professional courses, such as in Civil Engineering and Architecture. With the reform and practice of the core curriculum of Civil Engineering and Architecture, the vocational college has also upgraded its school-based teaching materials. In the new materials, there is a high proportion of contents related to the vocational skills examination, including personnel cost, data processing, construction supervision, and building information modeling (BIM). With the development of school-based teaching materials, the explanation of theoretical knowledge in the curriculum reform and practice links better with practical teaching. Therefore, other vocational colleges also need to actively participate in the development of school-based teaching materials along with the curriculum reform and practice.

\subsection{Improving the pertinence of practical teaching from the perspective of applied talent training}

It is also very important to improve the pertinence of practical teaching in the core curriculum of civil engineering courses from the perspective of applied talent training. It is an important matter which should not be disregarded in the curriculum reform and practice. For example, some vocational colleges are trying to cooperate with enterprises in the reform and practice of the core curriculum of Civil Engineering and Architecture, in order to create a link between professional course teaching inside the school and practical teaching outside the school. Under the " $1+X$ " system, considering the high demand of students for professional certificates, different students have different needs for different professional certificates. Therefore, in the selection of off-campus practical teaching bases and students' practical teaching posts, schools need to communicate with the students to promote the curriculum reform and better highlight the practical value by improving the pertinence of practical teaching.

\subsection{Strengthening the guidance in professional certificate examinations}

In the reform and practice of the core curriculum of Civil Engineering and Architecture, it is imperative to strengthen the guidance in relevant professional certificate examinations. In the specific curriculum reform and practice, professional curriculum teachers should communicate with the students in an in-depth manner about relevant professional certificate examinations and help students to meet their needs in preparing for various certificate examinations. In addition to explaining course knowledge in classroom teaching and cultivating students' professional skills in practical teaching, teachers should also regularly carry out teaching activities that are related to relevant professional certificate examinations in the overall teaching process. By interpreting specific tested points, professional knowledge, and skill requirements in these certificate examinations, students would be able to understand and learn about the difficulty and 
requirements of the corresponding certificates, thus lowering the perceived difficulty of the students in face with these examinations. Strengthening guidance in these examinations is an effective way in the curriculum reform and practice.

\section{Conclusion}

More attention should be paid to the reform and practice of the core curriculum of Civil Engineering and Architecture under the " $1+\mathrm{X}$ " system. Vocational colleges should provide guidance, while teachers should also actively try to do so. It has to be acknowledged that the corresponding curriculum reform and practice as well as the value of concrete efforts are not simple; in addition, the influence of a variety of factors also easily leads to certain problems. Therefore, vocational colleges and professional teachers should analyze the specific curriculum reform and practice as well as make targeted adjustments based on the results, thus providing more support for the curriculum reform and practice under the " $1+\mathrm{X}$ " system.

\section{Funding}

The General Project of Chongqing Higher Vocational Education Teaching Reform Research in 2021, "Reform and Practice of Core Curriculum of Civil Engineering and Architecture in Higher Vocational Colleges Based on '1+X' Certificate System” (Project Number: Z213269).

\section{Disclosure statement}

The author declares that there is no conflict of interest.

\section{References}

[1] Wang Y, Hu X, 2020, Research on Innovation and Practice of Talent Training Mode for Construction Majors under 1+X Certificate System. Shanxi Architecture, 2020(22): 185-187.

[2] Ren C, 2020, Practical Exploration of BIM Technology Foundation Course Construction in Higher Vocational Colleges under "1+X" Certificate System. Housing and Real Estate, 2020(15): 257.

[3] Liang J, 2020, Exploration on Curriculum Reform of Architectural Design Major in Higher Vocational Colleges Based on 1+X Certificate System. Journal of Jiamusi Education Institute, 2020(05): 216-217. 